\title{
Association between arterial stiffness, cerebral small vessel disease and cognitive impairment: A systematic review and meta-analysis
}

Citation for published version (APA):

van Sloten, T. T., Protogerou, A. D., Henry, R. M. A., Schram, M. T., Launer, L. J., \& Stehouwer, C. D. A. (2015). Association between arterial stiffness, cerebral small vessel disease and cognitive impairment: $A$ systematic review and meta-analysis. Neuroscience and Biobehavioral Reviews, 53, 121-130. https://doi.org/10.1016/j.neubiorev.2015.03.011

Document status and date:

Published: 01/06/2015

DOI:

10.1016/j.neubiorev.2015.03.011

Document Version:

Publisher's PDF, also known as Version of record

Document license:

Taverne

Please check the document version of this publication:

- A submitted manuscript is the version of the article upon submission and before peer-review. There can be important differences between the submitted version and the official published version of record.

People interested in the research are advised to contact the author for the final version of the publication, or visit the DOI to the publisher's website.

- The final author version and the galley proof are versions of the publication after peer review.

- The final published version features the final layout of the paper including the volume, issue and page numbers.

Link to publication

\footnotetext{
General rights rights.

- You may freely distribute the URL identifying the publication in the public portal. please follow below link for the End User Agreement:

www.umlib.nl/taverne-license

Take down policy

If you believe that this document breaches copyright please contact us at:

repository@maastrichtuniversity.nl

providing details and we will investigate your claim.
}

Copyright and moral rights for the publications made accessible in the public portal are retained by the authors and/or other copyright owners and it is a condition of accessing publications that users recognise and abide by the legal requirements associated with these

- Users may download and print one copy of any publication from the public portal for the purpose of private study or research.

- You may not further distribute the material or use it for any profit-making activity or commercial gain

If the publication is distributed under the terms of Article $25 \mathrm{fa}$ of the Dutch Copyright Act, indicated by the "Taverne" license above, 
Review

\title{
Association between arterial stiffness, cerebral small vessel disease and cognitive impairment: A systematic review and meta-analysis
}

\author{
Thomas T. van Sloten ${ }^{\mathrm{a}}$, Athanase D. Protogerou ${ }^{\mathrm{b}}$, Ronald M.A. Henry ${ }^{\mathrm{b}}$, \\ Miranda T. Schram ${ }^{\mathrm{b}}$, Lenore J. Launer ${ }^{\mathrm{c}}$, Coen D.A. Stehouwer ${ }^{\mathrm{b}, *}$ \\ a Department of Medicine, Cardiovascular Research Institute Maastricht and School for Nutrition, Toxicology and Metabolism, \\ Maastricht University Medical Centre, Prof. Debyelaan 25, Maastricht, The Netherlands \\ b Department of Medicine, Cardiovascular Research Institute Maastricht, Maastricht University Medical Centre, Prof. Debyelaan 25, Maastricht, \\ The Netherlands \\ c Intramural Research Program, Laboratory of Epidemiology and Population Sciences, National Institute on Aging, National Institutes of Health, \\ 7201 Wisconsin Avenue, Bethesda, MD, USA
}

\section{A R T I C L E I N F O}

\section{Article history:}

Received 24 July 2014

Received in revised form

14 December 2014

Accepted 22 March 2015

Available online 28 March 2015

\section{Keywords:}

Arterial stiffness

Cerebral small vessel disease

White matter hyperintensities

Cerebral microbleeds

Cerebral infarcts

Cognitive impairment

Dementia

Meta-analysis

Systematic review

\begin{abstract}
A B S T R A C T
Arterial stiffness may be a cause of cerebral small vessel disease and cognitive impairment. We therefore performed a systematic review and meta-analysis of studies on the association between stiffness, cerebral small vessel disease and cognitive impairment. For the associations between stiffness (i.e. carotid-femoral pulse wave velocity (cfPWV), brachial-ankle PWV (baPWV), carotid stiffness and pulse pressure) on the one hand and cerebral small vessel disease and cognitive impairment on the other, we identified 23 ( $n=15,666 / 20$ cross-sectional; 1 longitudinal; 2 combined cross-sectional/longitudinal) and 41 studies ( $n=57,671 / 26$ cross-sectional; 11 longitudinal; 4 combined cross-sectional/longitudinal), respectively. Pooled analyses of cross-sectional studies showed that greater stiffness was associated with markers of cerebral small vessel disease with odds ratios, per +1 SD, of $1.29-1.32(P<.001)$. Studies on cognitive impairment could not be pooled due to large heterogeneity. Some (but not all) studies showed an association between greater stiffness and cognitive impairment, and the strength of this association was relatively weak. The present study supports the hypothesis that greater arterial stiffness is a contributor to microvascular brain disease.
\end{abstract}

(c) 2015 Elsevier Ltd. All rights reserved.

Contents

1. Introduction

2. Methods

Data sources

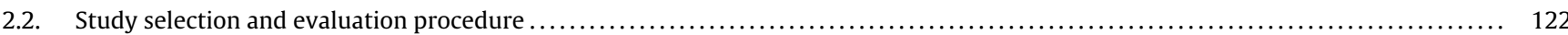

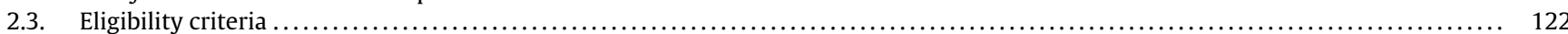

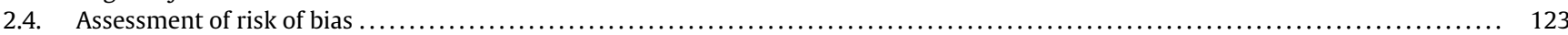

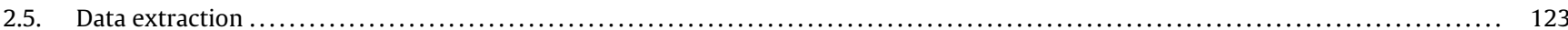

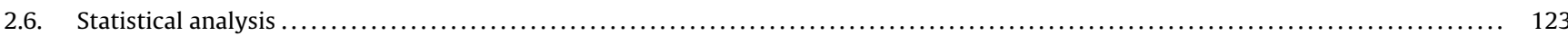

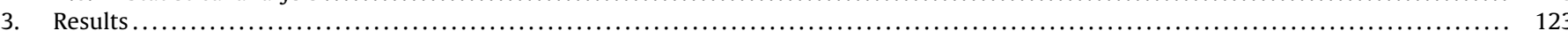

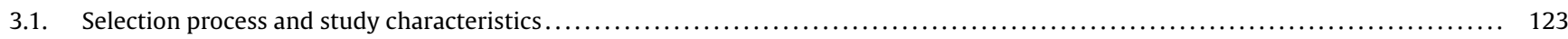

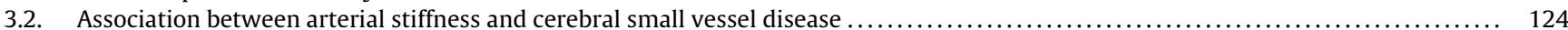

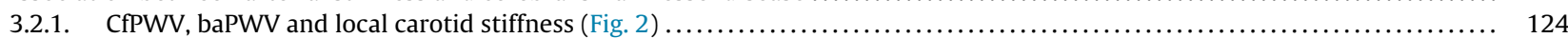

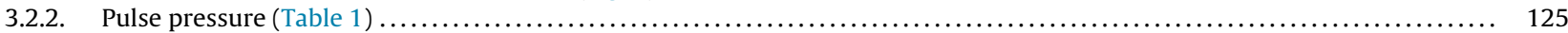

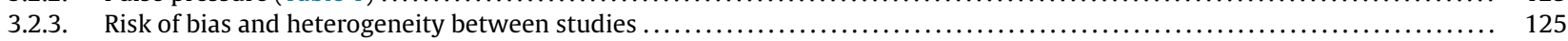

\footnotetext{
* Corresponding author at: Maastricht University Medical Centre, Department of Medicine, Prof. Debyelaan 25, 6229HX Maastricht, The Netherlands Tel.: +31 433871562; fax: +31433875006.

E-mail address: cda.stehouwer@mumc.nl (C.D.A. Stehouwer).
} 


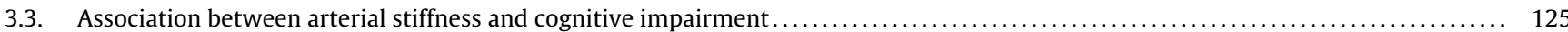

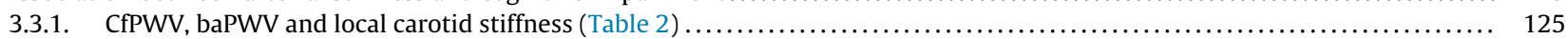

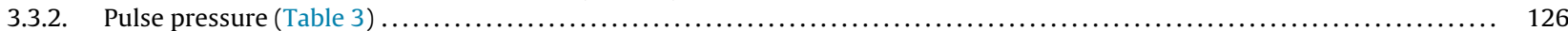

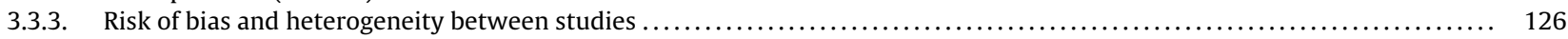

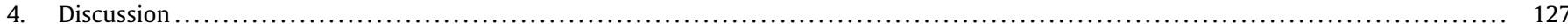

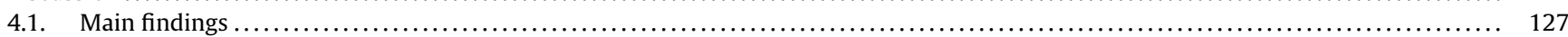

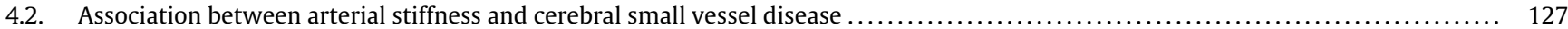

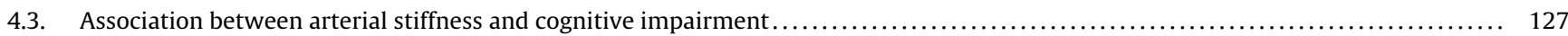

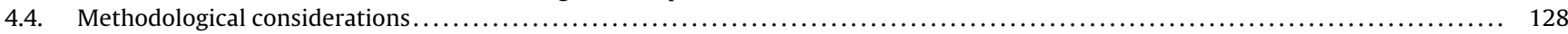

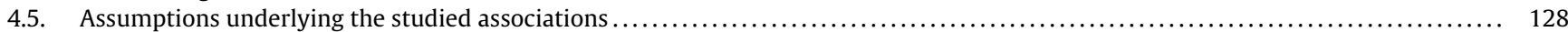

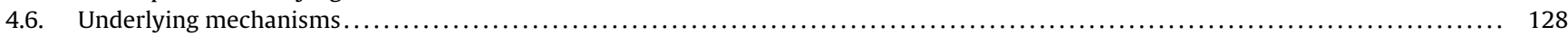

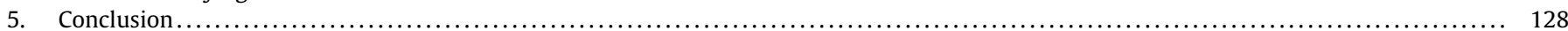

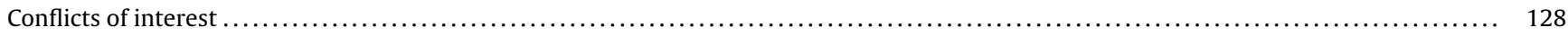

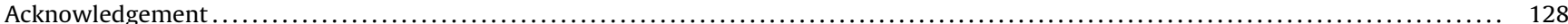

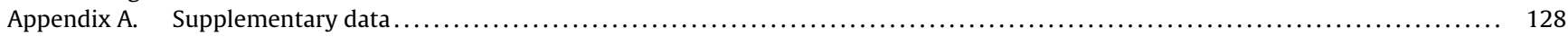

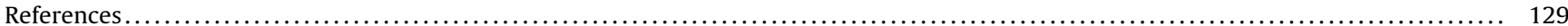

\section{Introduction}

Increased arterial stiffness leads to an increased pulsatile pressure and flow load, which can damage the microcirculation (Mitchell, 2008; O'Rourke and Safar, 2005; Tzourio et al., 2014). The brain is more vulnerable for this increased load, because its microcirculation is characterized by low impedance, allowing the pulsatile load to penetrate deeply into its microvascular bed (Mitchell, 2008; O'Rourke and Safar, 2005; Tzourio et al., 2014). In the brain, microvascular damage can manifest itself as white matter hyperintensities (WMH), cerebral microbleeds and lacunar infarcts (Wardlaw et al., 2013b), which may ultimately result in cognitive impairment, including dementia (Mitchell et al., 2011).

Currently, consistent evidence is lacking, however, to support an association between increased arterial stiffness on the one hand and cerebral small vessel disease and cognitive impairment on the other, despite the fact that in recent years a growing number of studies have been done on this issue. Existing studies were done in diverse study populations and evaluated different measures of cerebral small vessel disease, cognitive function and arterial stiffness. Measures of arterial stiffness included carotid-femoral pulse wave velocity (cfPWV), brachial-ankle PWV (baPWV) and local distensibility measurements of the carotid artery (i.e. local carotid stiffness). These indices reflect stiffening of different parts of the arterial tree, and may be differentially associated with cerebral small vessel disease and cognitive impairment (Safar and O'Rourke, 2006). In addition, some studies used pulse pressure (PP) (i.e. the difference between systolic and diastolic blood pressure) as a surrogate measure of arterial stiffness. PP is, however, determined by factors other than arterial stiffness, including stroke volume and wave reflections (Safar and O'Rourke, 2006). This may affect the association between arterial stiffness and cerebral small vessel disease and cognitive impairment.

Three previous reviews (Pase et al., 2012; Rabkin and Jarvie, 2011; Singer et al., 2014) have examined the association between arterial stiffness and microvascular brain disease. However, these studies evaluated only cognitive impairment (Pase et al., 2012; Rabkin and Jarvie, 2011), included a limited number of measures of arterial stiffness and cognitive impairment (Pase et al., 2012; Rabkin and Jarvie, 2011), included only studies done in healthy individuals (Singer et al., 2014), did not perform a study quality assessment (Pase et al., 2012; Rabkin and Jarvie, 2011; Singer et al., 2014) and(or) did not do a meta-analysis (Singer et al., 2014).

In view of the above, we performed a systematic review and meta-analysis of observational studies on the association between, on the one hand, arterial stiffness (i.e. cfPWV, baPWV, local carotid stiffness and PP) and, on the other, markers of cerebral small vessel disease and cognitive impairment.

\section{Methods}

This systematic review and meta-analysis is reported in accordance with the PRISMA guidelines (Moher et al., 2009) (the PRISMA checklist is provided as Supplementary material).

\subsection{Data sources}

We identified relevant studies through a search of Medline and Embase from inception to July 18, 2014 (search terms are provided as Supplementary material). In addition, we identified studies by reviewing the reference lists of all relevant articles identified.

\subsection{Study selection and evaluation procedure}

Two reviewers (TVS and AP) selected independently all relevant studies based on title and abstract, retrieved selected full texts, performed an eligibility assessment, assessed risk of bias and extracted data from each eligible study (described below). Any disagreements between the reviewers were resolved by consensus.

\subsection{Eligibility criteria}

Human studies were eligible if they met the following criteria: (1) cross-sectional or longitudinal in design; (2) sample size $n \geq 150$; (2) investigated an association between, on the one hand, arterial stiffness and, on the other, markers of cerebral small vessel disease and(or) cognitive function; and (3) measured arterial stiffness by cfPWV, baPWV or local carotid arterial stiffness, and(or) measured PP, either at the level of the brachial artery (i.e. peripheral PP) or carotid artery or aorta (i.e. central PP). Case-control studies were excluded, because these studies, in general, have a relatively low internal validity. For cerebral small vessel disease, we selected all studies with data on any of the following magnetic resonance imaging (MRI)-detected markers: WMH, cerebral microbleeds and lacunar infarcts (Wardlaw et al., 2013b). In addition, most silent infarcts (i.e. infarcts detected in individuals without a history of stroke/transient ischaemic attack) and subcortical infarcts (i.e. cerebral infarcts in the deep brain regions not extending into the cortex) are lacunar (Wardlaw et al., 2013b), and were also included. Studies that used computed tomography (CT) to detect markers of cerebral small vessel disease were excluded, because CT is less sensitive than MRI (Wardlaw et al., 2013b). For cognitive function, we selected all studies with data on any measure of global and(or) domain-specific cognitive function. Only papers 
written in English were included. For studies that published more than one article based upon overlapping groups of participants, with the same outcome measure and study design, we included the study with the largest number of participants.

\subsection{Assessment of risk of bias}

Risk of bias was evaluated with a slightly modified version of the Newcastle Ottawa Scale (NOS) (Wells et al.) (NOS is provided as Supplementary material). The NOS includes items on participant selection, validity of measurements, whether or not results were adjusted for age, systolic and(or) mean blood pressure, and (for studies on cognitive function) education, plus (for longitudinal studies) duration and completeness of follow-up.

\subsection{Data extraction}

Information on the following items was extracted from each study with use of a standardized form: design, sample size, population characteristics, measures of arterial stiffness, cerebral small vessel disease and cognitive impairment, unadjusted and(or) adjusted results and variable(s) that were adjusted for in the original analyses. Classification of cognitive domains and included cognitive function tests are described in Table S1 (Supplementary material). Additional data were requested for two studies (KearneySchwartz et al., 2009; Nomura et al., 2010) from corresponding authors; one (Nomura et al., 2010) provided the requested data.

\subsection{Statistical analysis}

We intended to pool results of studies that were sufficiently homogeneous with regard to study methodology and statistical analysis. However, such a meta-analysis was methodologically possible only for the cross-sectional association between cfPWV, baPWV and local carotid stiffness on the one hand and markers of cerebral small vessel disease on the other. Results of studies on PP or cognitive impairment could not be pooled due to a large heterogeneity between studies (see below).
For the meta-analysis, results were pooled for the association between cfPWV, baPWV and local carotid stiffness on the one hand and a categorical measure of cerebral small vessel disease on the other. When more than two categories were present for $\mathrm{WMH}$, we used the odds ratio (OR) for the highest compared to the lowest category. For studies that measured deep and periventricular WMH separately and did not provide a measure of total $\mathrm{WMH}$, we included the results for periventricular WMH only, because periventricular WMH is more closely related to total WMH (DeCarli et al., 2005). For studies that measured lobar and deep cerebral microbleeds separately and did not provide a measure of total microbleeds, we included the results for deep microbleeds only, because deep microbleeds are more strongly associated with microvascular damage (Poels et al., 2010). Pooled standardized ORs were calculated with the use of the random-effects inverse variance method. If available, we included the fully adjusted value for the OR. Heterogeneity between studies was investigated with Higgins $I^{2}$ statistic and Cochran's $Q$ test. An $I^{2}>50 \%$ and(or) a $Q$ test $P$-value $<.05$ indicated statistical heterogeneity. Funnel plots were used to evaluate potential publication bias. The meta-analysis was performed with Cochrane Review Manager Version 5.2.

\section{Results}

\subsection{Selection process and study characteristics}

Fig. 1 shows the selection process of included studies. Of the 23 studies included on cerebral small vessel disease ( $n=15,666 ; 20$ cross-sectional; 1 longitudinal; 2 combined crosssectional/longitudinal), eight evaluated $\operatorname{cfPWV}(n=5017), 7 \mathrm{baPWV}$ $(n=3176), 1$ local carotid stiffness $(n=912)$ and $12 \mathrm{PP}(n=10,775$; 8 office PP, 2 ambulatory PP, 3 central PP). Of the 41 studies on cognitive impairment $(n=57,671 ; 26$ cross-sectional; 11 longitudinal; 4 combined cross-sectional/longitudinal), 13 evaluated cfPWV ( $n=12,578), 4$ baPWV $(n=1313), 1$ local carotid stiffness $(n=3714)$ and $28 \mathrm{PP}(n=50,408 ; 26$ office PP, 3 central PP). Markers of cerebral small vessel disease studied were WMH (17 studies), microbleeds ( 6 studies) and infarcts (10 studies). Measures of cognitive function included dementia ( 8 studies) and tests of global cognitive
A : cerebral small vessel disease

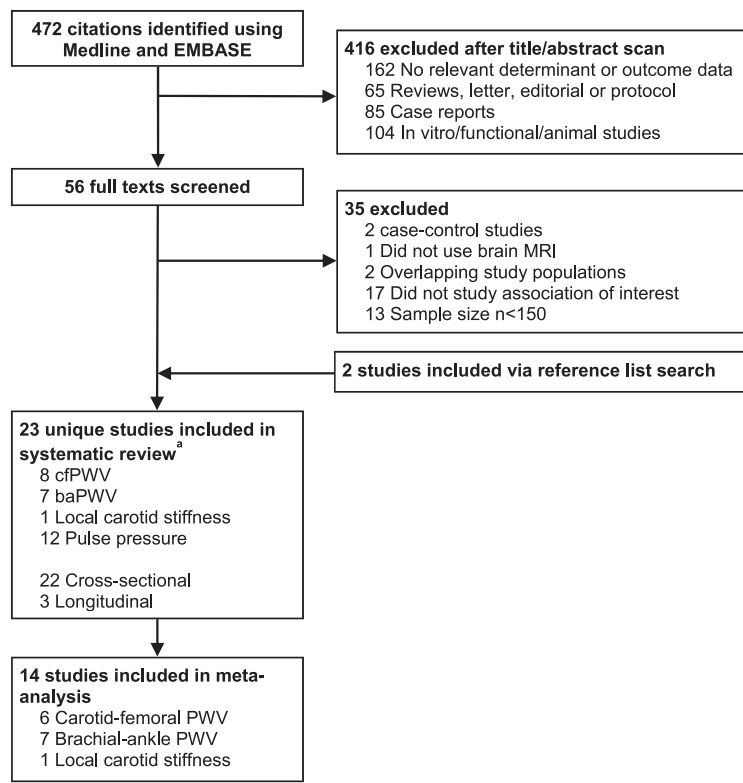

B : cognitive impairment

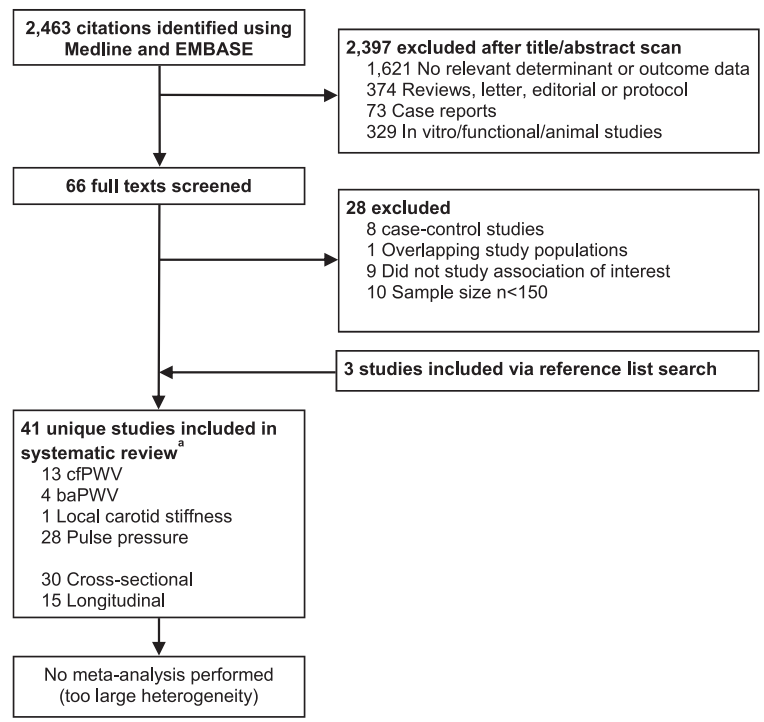


(panel B). ${ }^{a}$ Some studies evaluated multiple stiffness indices and included both a cross-sectional and a longitudinal data analysis. 


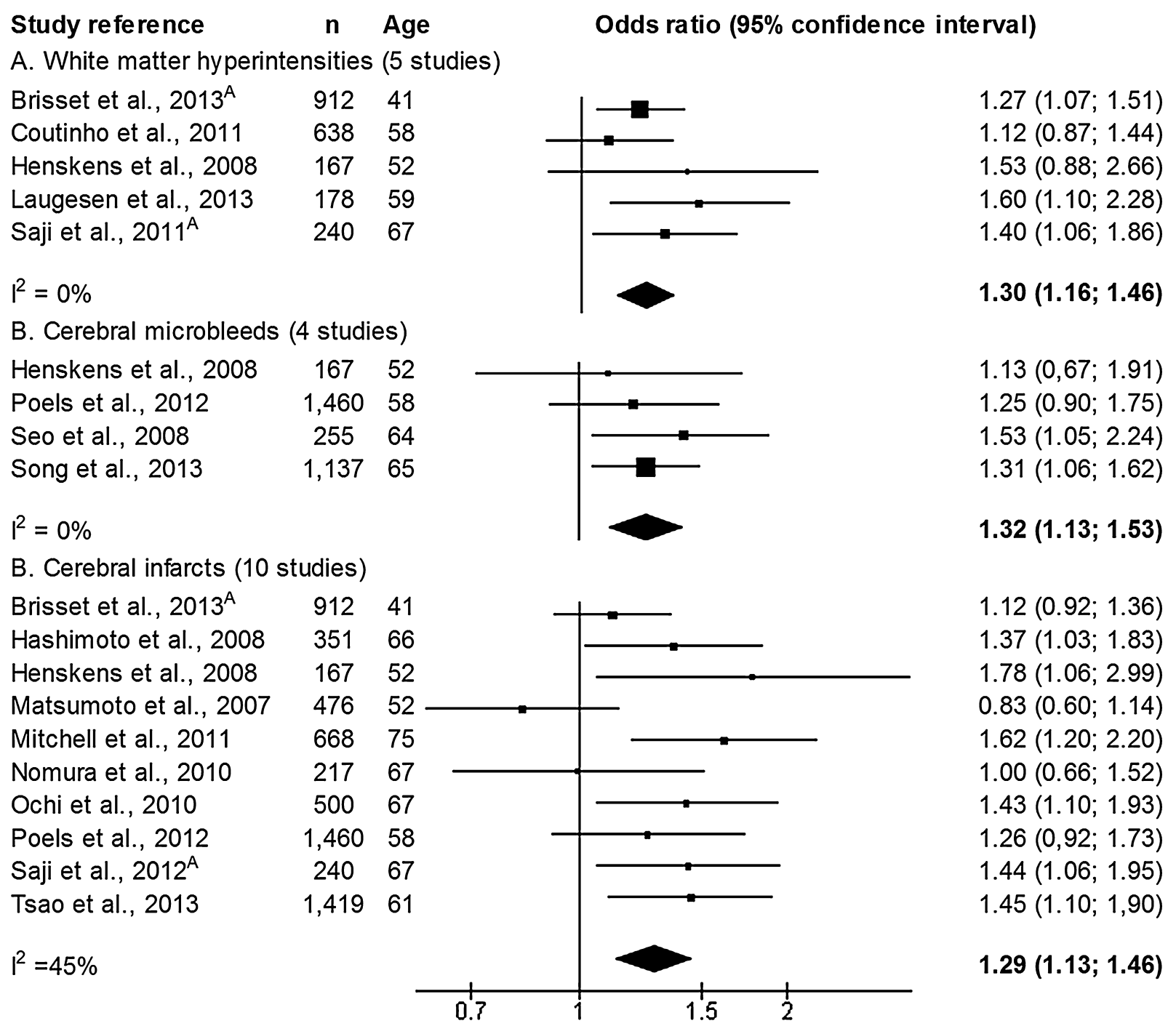

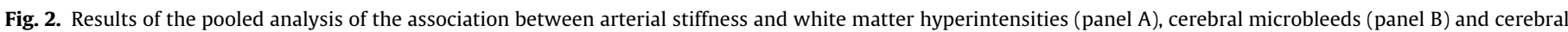

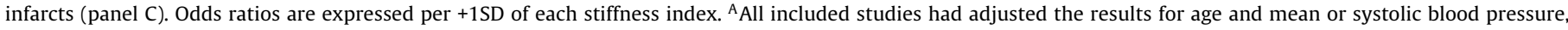

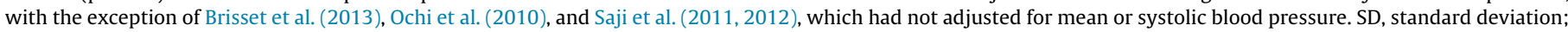

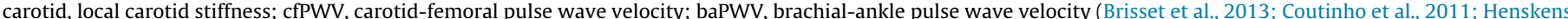

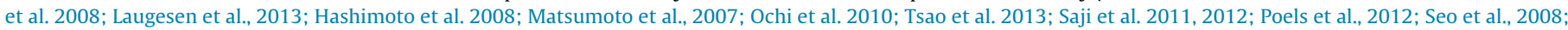
Song et al., 2013; Mitchell et al. 2011; Nomura et al., 2010).

function (26 studies), memory (14 studies), processing speed (13 studies) and executive function/attention (16 studies). The studies were conducted in the general population, or in selected clinical populations (e.g. individuals with diabetes, hypertension, stroke or Alzheimer's disease) (references and full study characteristics are provided as Supplementary material, Tables S2-S5).

\subsection{Association between arterial stiffness and cerebral small vessel disease}

\subsubsection{CfPWV, baPWV and local carotid stiffness (Fig. 2)}

Of the 15 cross-sectional studies included on the association between cfPWV, baPWV and local carotid stiffness on the one hand and markers of cerebral small vessel disease on the other, eleven (73\%) showed a statistically significant association between greater arterial stiffness and cerebral small vessel disease.

The one longitudinal study (Rosano et al., 2013) (Health Ageing and Body Composition study; $n=303$, mean follow-up duration 7 years) showed a significant association between baseline cfPWV and $\mathrm{WMH}$ volume in the left superior longitudinal fasciculus at follow-up (for $\geq$ versus < median $\mathrm{WMH}$ volume in this region, standardized OR: 1.47 (95\%CI 1.10; 1.95)).

For the pooled analysis, 14 cross-sectional studies $(n=8618)$ were included (no longitudinal studies), of which six had measured cfPWV, seven baPWV and one local carotid stiffness. One cross-sectional study ( $n=184$ ) (Kearney-Schwartz et al., 2009) was excluded from this analysis because this study did not provide sufficient data. The pooled analyses showed that arterial stiffness was statistically significantly associated with WMH (Fig. 2, panel A), cerebral microbleeds ( panel B) and cerebral infarcts (panel C). There was no significant statistical heterogeneity (Fig. 2). In addition, there was no funnel plot asymmetry (see Supplementary material, Fig. S1). When we performed the pooled analyses separately for baPWV and cfPWV, both indices were associated with markers of cerebral small vessel disease (ORs for +1SD cfPWV $1.39(95 \% \mathrm{Cl}$ $1.21 ; 1.60)$ and for +1SD baPWV $1.26(95 \%$ CI $1.08 ; 1.46)$ ) (see Supplementary material, Fig. S2). In addition, when we repeated the analysis after excluding studies with a relatively high risk of bias (NOS score $\leq 3$; two studies), results did not materially change (data not shown). 
Table 1

Summary of study results on the association between pulse pressure and cerebral small vessel disease.

\begin{tabular}{|c|c|c|c|c|c|c|c|c|}
\hline \multirow[t]{2}{*}{ Reference } & \multirow[t]{2}{*}{ Index } & \multirow[t]{2}{*}{$n$} & \multirow[t]{2}{*}{ Age (y) } & \multicolumn{3}{|c|}{$\begin{array}{l}\text { Standardized effect estimate or direction of } \\
\text { association }^{\mathrm{a}}\end{array}$} & \multicolumn{2}{|c|}{ Adjustments } \\
\hline & & & & WMH & Microbleeds & Infarcts & Age & Blood pressure \\
\hline \multicolumn{9}{|l|}{ Cross-sectional studies (12 studies) } \\
\hline Poels et al. (2010)/Verhaaren et al. (2013)b & off & 3979 & 60 & $\beta 0.08^{*}$ & OR 1.09 & & $\mathrm{x}$ & \\
\hline Tsao et al. (2013) & cent & 1419 & 61 & $\beta 0.002$ & & OR 0.97 & $\mathrm{x}$ & $\mathrm{x}$ \\
\hline Liao et al. (1997) (1) ${ }^{\mathrm{c}}$ & off & 843 & 63 & OR 1.32 & & & $\mathrm{x}$ & \\
\hline Liao et al. (1997) (2) ${ }^{c}$ & off & 728 & 61 & OR $2.17^{*}$ & & & $\mathrm{x}$ & \\
\hline Aribisala et al. (2014) & off & 694 & 73 & $\beta 0.04$ & & & $\mathrm{x}$ & \\
\hline Kim et al. (2011) & off & 692 & 63 & $+*$ & & & $\mathrm{x}$ & $\mathrm{x}$ \\
\hline Mitchell et al. (2011) & cent & 668 & 75 & $\beta-0.02$ & & OR $1.71^{*}$ & $\mathrm{x}$ & $\mathrm{x}$ \\
\hline Ochi et al. $(2010)^{\mathrm{d}}$ & off & 500 & 67 & & & OR 1.10 & $\mathrm{x}$ & \\
\hline Kim et al. (2012) & off & 236 & 66 & $+^{*}$ & & & $\mathrm{x}$ & \\
\hline Naganuma et al. (2011) & off & 179 & 58 & & OR $1.73^{*}$ & & & $\mathrm{x}$ \\
\hline Kwon et al. (2014) & amb & 169 & 66 & + & & & $\mathrm{x}$ & $\mathrm{x}$ \\
\hline Henskens et al. (2008) & $\mathrm{amb}$ & 167 & 52 & OR 0.90 & OR 0.93 & OR 0.93 & $\mathrm{x}$ & $\mathrm{x}$ \\
\hline De Leeuw et al. (2004) & off & 152 & 68 & + & & & $\mathrm{x}$ & \\
\hline \multicolumn{9}{|l|}{ Longitudinal studies (2 studies) } \\
\hline Verhaaren et al. (2013) & off & 655 & 62 & $+^{*}$ & & & $\mathrm{x}$ & \\
\hline Van Dooren et al. (2014) & amb & 169 & 53 & & OR 1.95 & & $\mathrm{x}$ & \\
\hline
\end{tabular}

Studies are ordered from largest to smallest sample size.

a If available, (fully adjusted) standardized effect estimates are presented. If not, direction of association is presented.

+: higher PP associated with higher prevalence/incidence of markers of cerebral small vessel disease.

-: higher PP associated with lower prevalence/incidence of markers of cerebral small vessel disease.

$=:$ no association between PP and cerebral small vessel disease; direction of association not indicated in original manuscript.

b Studies based on an overlapping population (Rotterdam study). Poels et al. (2010) describes the association between PP and microbleeds in the total population ( $n=3979$ ). Verhaaren et al. (2013) describes in a subsample $(n=655)$ the association between PP and WMH.

c Analyses stratified for European-Americans (1) and African-Americans (2). Results not available for the total study population.

d Ochi et al. (2010) also evaluated the association between office PP and WMH; results for office PP were qualitatively similar to results for central PP.

$\mathrm{y}$, years; WMH, white matter hyperintensities; OR, odds ratio; off, office pulse pressure; amb, ambulatory pulse pressure; cent, central pulse pressure.

* $P<.05$.

\subsubsection{Pulse pressure (Table 1)}

Studies on the association between PP and cerebral small vessel disease differed markedly with regard to the statistical analysis performed. For instance, studies modelled PP as a continuous and categorical variable and calculated standardized and unstandardized effect estimates. Hence, a pooled analysis was not possible. Nevertheless, 6 of the 12 (50\%) cross-sectional studies included showed a statistically significant association between higher PP and markers of cerebral small vessel disease. The reported standardized regression coefficients ranged from -0.02 to 0.08 , and the standardized ORs from 0.90 to 2.17 .

Of the two longitudinal studies, one (Verhaaren et al., 2013) (Rotterdam Study; $n=655$, mean follow-up duration 3.5 years) showed a statistically significant association between higher baseline PP and increase in WMH over time (regression coefficient per +1 SD PP for decline in ml WMH volume/year: -0.04 (95\%CI 0.00; $0.08)$ ). The other study (Van Dooren et al., 2014) included individuals with hypertension ( $n=169$; mean follow-up duration 2 years) and showed a not statistically significant association between higher baseline ambulatory PP and progression of CMB over time (standardized OR 1.95 (95\%CI 0.95; 3.90)).

\subsubsection{Risk of bias and heterogeneity between studies}

Risk of bias among the included studies is presented in detail in Table S6 (Supplementary material). There was a moderate risk of bias of across the studies on cerebral small vessel disease (79\% of the studies scored $\geq 80 \%$ of the total points on the NOS). A lower NOS score was primarily due to the failure to adjust in the analysis for systolic or mean blood pressure ( $46 \%$ of the studies). In general, the directionality of the effects did not relate to risk of bias. Studies that found a significant association between greater arterial stiffness and cerebral small vessel disease as compared to those studies which did not find such an association did not differ with regard to the variables that they adjusted for in the analysis (i.e. $50 \%$ of significant studies had adjusted for age and blood pressure versus
$54 \%$ of the nonsignificant studies, $P$-value $=.83$ ). In addition, there were no differences between significant and nonsignificant studies with regard to sample size (mean $n=778$ versus $n=521$ ), age of the study population (mean age: 65.5 versus 60.8 years), type of population studied (56\% and $44 \%$ of significant studies were conducted in general healthy populations and selected clinical populations, respectively, versus $31 \%$ and $69 \%$ of the nonsignificant studies), and total NOS score (for cross-sectional studies, mean score: 4.1 versus 3.8 points; for longitudinal studies, mean score: 6.0 versus 4.0 points) ( $P$-values $>.07)$.

\subsection{Association between arterial stiffness and cognitive impairment}

\subsubsection{CfPWV, baPWV and local carotid stiffness (Table 2)}

Studies on the association between cfPWV, baPWV and local carotid stiffness on the one hand and cognitive impairment on the other differed markedly with regard to the methodology used. For instance, studies used many different tests of cognitive function and performed different statistical analyses. Hence, a pooled analysis was not possible. Of the 11 cross-sectional studies included on global cognitive impairment (i.e. assessment of dementia or global cognition test), six (55\%) showed a statistically significant association with greater arterial stiffness. In addition, memory was studied in eight cross-sectional studies: two found a statistically significant negative association with greater arterial stiffness. For processing speed, two out of seven, and for executive function/attention, one out of seven cross-sectional studies reported a statistically significant negative association. The reported standardized regression coefficients ranged from -0.05 to 0.20 .

Of the four longitudinal studies included (mean follow-up duration ranged from 1 to 11 years), three showed a significant association between greater arterial stiffness and global cognitive decline. Three longitudinal studies also reported data on cognitive decline in specific domains. Only one study found a 
Table 2

Summary of study results on the association between cfPWV, baPWV and local carotid stiffness on the one hand and cognitive impairment on the other.

\begin{tabular}{|c|c|c|c|c|c|c|c|c|c|c|}
\hline \multirow[t]{2}{*}{ Reference } & \multirow[t]{2}{*}{ Index } & \multirow[t]{2}{*}{$n$} & \multirow[t]{2}{*}{ Age (y) } & \multicolumn{5}{|c|}{ Standardized effect estimate or direction of association ${ }^{\mathrm{a}}$} & \multicolumn{2}{|c|}{ Adjustments } \\
\hline & & & & Dementia & Global score & Memory & Processing speed & $\mathrm{EF} / \mathrm{A}$ & Age & Blood pressure \\
\hline \multicolumn{11}{|c|}{ Cross-sectional studies (15 studies) } \\
\hline Poels et al. $(2007)^{b}$ & cfPWV & 3714 & 72 & & + & & + & $+*$ & $\mathrm{x}$ & $\mathrm{x}$ \\
\hline Tsao et al. (2013) & cfPWV & 1578 & 61 & & & $\beta-0.01$ & & $\beta 0.07$ & $\mathrm{x}$ & $\mathrm{x}$ \\
\hline Zhong et al. (2013) & cfPWV & 1433 & 75 & & $+^{*}$ & $+*$ & + & + & $\mathrm{x}$ & \\
\hline Mitchell et al. (2011) & cfPWV & 668 & 75 & & & $\beta 0.10^{*}$ & $\beta-0.03$ & $\beta 0.08$ & $\mathrm{x}$ & $\mathrm{x}$ \\
\hline Watson et al. (2011) & cfPWV & 552 & 73 & & $\beta 0.11^{*}$ & $\beta 0.07$ & $\beta 0.12^{*}$ & & $\mathrm{x}$ & $\mathrm{x}$ \\
\hline Elias et al. (2009) & cfPWV & 409 & 61 & & $=$ & $=$ & $\beta 0.13^{*}$ & & $\mathrm{x}$ & $\mathrm{x}$ \\
\hline Muller et al. (2007) & cfPWV & 396 & 60 & & & $\beta 0.01$ & $\beta 0.02$ & $\beta 0.01$ & $\mathrm{x}$ & \\
\hline Sugawara et al. (2010) & baPWV & 388 & 69 & & + & & & & $\mathrm{x}$ & $\mathrm{x}$ \\
\hline Kim et al. (2009) & baPWV & 370 & 55 & & $=$ & & & & & \\
\hline Fujiwara et al. (2005) & baPWV & 352 & 77 & & $+^{*}$ & & & & $\mathrm{x}$ & $\mathrm{x}$ \\
\hline Singer et al. (2013) & cfPWV & 319 & 80 & & $\beta-0.05$ & $\beta 0.20$ & $\beta 0.05$ & $\beta-0.03$ & $\mathrm{x}$ & $\mathrm{x}$ \\
\hline Hanon et al. (2005) & cfPWV & 308 & 78 & OR $2.63^{*}$ & + & & & & $\mathrm{x}$ & $\mathrm{x}$ \\
\hline Scuteri et al. (2013) & cfPWV & 280 & 78 & & + & & & & $\mathrm{x}$ & \\
\hline Fukuhara et al. (2006) & baPWV & 203 & 85 & & $+^{*}$ & & & & $\mathrm{x}$ & $\mathrm{x}$ \\
\hline Kearney-Schwartz et al. (2009) & cfPWV & 198 & 69 & & & $=$ & & $=$ & & \\
\hline \multicolumn{11}{|l|}{ Longitudinal studies (4 studies) } \\
\hline Poels et al. (2007) & cfPWV & 2767 & 71 & HR 0.91 & OR $0.93^{c}$ & & OR $1.09^{c}$ & OR $1.10^{c}$ & $\mathrm{x}$ & $\mathrm{x}$ \\
\hline $\begin{array}{l}\text { Zeki Al Hazzouri et al. } \\
\text { (2013)/Watson et al. (2011) }\end{array}$ & cfPWV & 2488 & 74 & & + & + & - & & $\mathrm{x}$ & $\mathrm{x}$ \\
\hline Benetos et al. (2012) & cfPWV & 873 & 88 & & $+*$ & & & & $\mathrm{x}$ & $\mathrm{x}$ \\
\hline Waldstein et al. (2008) & cfPWV & 582 & 54 & & $+{ }^{*}$ & $+^{*}$ & + & + & $\mathrm{x}$ & $\mathrm{x}$ \\
\hline
\end{tabular}

Studies are ordered from largest to smallest sample size.

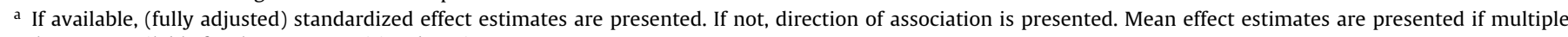
results were available for the same cognitive domain.

+: greater arterial stiffness associated with worse cognitive function.

-: greater arterial stiffness associated with better cognitive function.

$=:$ no association between arterial stiffness and cognitive function; direction of association not indicated in original manuscript.

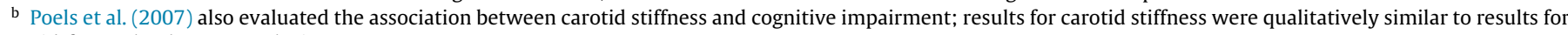
carotid-femoral pulse wave velocity.

c Cognitive decline specified as >-1SD change of the mean difference between examinations.



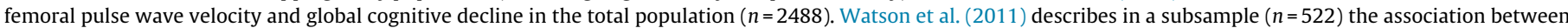
carotid-femoral pulse wave velocity and global cognitive decline, memory and processing speed.

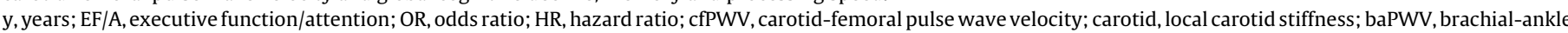
pulse wave velocity.

* $P<.05$.

statistically significant association between greater arterial stiffness and decline in memory. Associations with cognitive decline in other specific domains (i.e. processing speed and executive function/attention) were not statistically significant. The reported standardized ORs/HRs ranged from 0.91 to 1.10 .

\subsubsection{Pulse pressure (Table 3)}

In general, studies on the association between PP and cognitive impairment had more heterogeneous results than those on cfPWV, baPWV and local carotid stiffness and cognitive impairment. Of the 13 cross-sectional studies included on global cognitive impairment, four (31\%) showed a statistically significant association with greater PP. In addition, memory was studied in seven cross-sectional studies: four found a statistically significant negative association with greater PP. For processing speed, two out of six, and for executive function/attention, two out of nine cross-sectional studies reported a statistically significant negative association. The reported standardized regression coefficients ranged from -0.02 to 0.16 . In contrast, three studies (Davis et al., 2003; Molander et al., 2010; van Bruchem-Visser et al., 2009) found a statistically significant association, but in the opposite direction, i.e. between higher PP and better (global and(or) domain-specific) cognitive function (Table 3). These studies were done in individuals with Alzheimer's disease (Davis et al., 2003; van Bruchem-Visser et al., 2009) or in the oldest old (i.e. individuals $\geq 85$ years) (Molander et al., 2010).

Of the 13 longitudinal studies on global cognitive decline (mean duration of follow-up ranged from 1 to 14 years), three (23\%) showed a statistically significant association with greater PP. In addition, three longitudinal studies also reported data on cognitive decline in specific domains. All studies found a significant association with decline in executive function/attention and one with decline in memory, but none found a statistically significant association with processing speed. In addition, one study (Qiu et al., 2003) found a U-shaped association between PP and cognitive decline, whereas one study (Sabayan et al., 2012) found a statistically significant association between higher PP and lower cognitive decline. The latter two studies were both done in older individuals (mean age 82 and 85 years, respectively) (Table 3 ). The reported standardized ORs ranged from 0.85 to 1.21 .

\subsubsection{Risk of bias and heterogeneity between studies}

There was a moderate risk of bias of across the studies on cognitive impairment $(62 \%$ of the studies scored $\geq 80 \%$ of the total points on the NOS) (individual NOS scores are provided as Supplementary material, Table S6). A lower NOS score was primarily due to the failure to adjust in the analysis for systolic or mean blood pressure $(52 \%$ of the studies). Studies that found a significant association between arterial stiffness and cognitive impairment as compared to those studies which did not find such an association had a smaller sample size (mean $n=1190$ versus $n=1737$ ), but this difference was not statistically significant $(P$-value $=.49)$. There were no differences between significant and nonsignificant studies with regard to the variables that they adjusted for in the analysis (i.e. $58 \%$ of significant studies had adjusted for age, education and blood pressure versus $39 \%$ of the nonsignificant studies), age of the study population (mean age: 70.0 versus 71.4 years), type of population studied 
Table 3

Summary of study results on the association between pulse pressure and cognitive impairment.

\begin{tabular}{|c|c|c|c|c|c|c|c|c|c|c|}
\hline \multirow[t]{2}{*}{ Reference } & \multirow[t]{2}{*}{ Index } & \multirow[t]{2}{*}{$n$} & \multirow[t]{2}{*}{ Age $(y)$} & \multicolumn{5}{|c|}{ Standardized effect estimate or direction of association ${ }^{\mathrm{a}}$} & \multicolumn{2}{|c|}{ Adjustments } \\
\hline & & & & Dementia & Global score & Memory & Processing speed & $\mathrm{EF} / \mathrm{A}$ & Age & Blood pressure \\
\hline \multicolumn{11}{|l|}{ Cross-sectional studies (17 studies) } \\
\hline Tsivgoulis et al. (2009) & off & 19,836 & 65 & & OR 0.98 & & & & $\mathrm{x}$ & \\
\hline Obisesan et al. (2008) & off & 5408 & 71 & & $++^{*}$ & & & & $\mathrm{x}$ & \\
\hline Tsao et al. (2013) & cent & 1578 & 61 & & & $\beta 0.07^{*}$ & & $\beta 0.02$ & $\mathrm{x}$ & $\mathrm{x}$ \\
\hline Robbins et al. (2005) & off & 1563 & 49 & & $+*$ & $+*$ & $+{ }^{*}$ & $=$ & $\mathrm{x}$ & $\mathrm{x}$ \\
\hline Mitchell et al. (2011) & cent & 668 & 75 & & & $\beta 0.11^{*}$ & $\beta-0.02$ & $\beta 0.09$ & $\mathrm{x}$ & $\mathrm{x}$ \\
\hline Davis et al. (2003) & off & 609 & 74 & & $-{ }^{*}$ & $-^{*}$ & $=$ & $-{ }^{*}$ & $\mathrm{x}$ & \\
\hline Sabayan et al. (2012) & off & 572 & 85 & & - & & & & $\mathrm{x}$ & \\
\hline Chrysohoou et al. (2012) & off & 535 & 75 & & OR $1.41^{*}$ & & & & $\mathrm{x}$ & \\
\hline Pase et al. $(2013)^{\mathrm{b}}$ & cent & 493 & 53 & & & $\beta 0.12^{*}$ & $\beta 0.14^{*}$ & $\beta 0.16^{*}$ & $\mathrm{x}$ & $\mathrm{x}$ \\
\hline Molander et al. (2010) & off & 476 & 90 & & $-^{*}$ & & & & $\mathrm{x}$ & \\
\hline Fujiwara et al. (2005) & off & 352 & 77 & & $+{ }^{*}$ & & & & $\mathrm{x}$ & \\
\hline Yasar et al. (2011) & off & 337 & 74 & & - & $=$ & + & + & $\mathrm{x}$ & \\
\hline van Bruchem-Visser et al. (2009) & off & 327 & 77 & & $-{ }^{*}$ & & & & $\mathrm{x}$ & \\
\hline Giang et al. (2013) & off & 314 & 63 & & + & + & + & - & $\mathrm{x}$ & \\
\hline Kalaitzidis et al. (2013) & off & 256 & 53 & & + & & & $++^{*}$ & $\mathrm{x}$ & \\
\hline Fukuhara et al. (2006) & off & 203 & 85 & & + & & & & $\mathrm{x}$ & $\mathrm{x}$ \\
\hline Raz et al. (2011) & off & 158 & 52 & & & & & $=$ & $\mathrm{x}$ & \\
\hline \multicolumn{11}{|l|}{ Longitudinal studies (13 studies) } \\
\hline Peters et al. (2013) & off & 3337 & 84 & $+{ }^{*}$ & & & & & & \\
\hline Freitag et al. (2006) (1) & off & 2505 & 58 & + & & & & & $\mathrm{x}$ & \\
\hline Freitag et al. (2006) $(2)^{c}$ & off & 2505 & 77 & - & & & & & $\mathrm{x}$ & \\
\hline Lee et al. (2013) & off & 1925 & 73 & & + & & & & $\mathrm{x}$ & $\mathrm{x}$ \\
\hline Ogunniyi et al. (2011) & off & 1753 & 76 & OR $1.21^{*}$ & & & & & $\mathrm{x}$ & \\
\hline Waldstein et al. (2008) & off & 1749 & 57 & & $+*$ & $+*$ & + & $+{ }^{*}$ & $\mathrm{x}$ & $\mathrm{x}$ \\
\hline Taylor et al. (2013) & off & 1484 & 50 & & - & & & & $\mathrm{x}$ & \\
\hline Qiu et al. (2003) & off & 1270 & 82 & $U^{*}, d$ & & & & & $\mathrm{x}$ & $\mathrm{x}$ \\
\hline Benetos et al. (2012) & off & 873 & 88 & & $=$ & & & & $\mathrm{x}$ & $\mathrm{x}$ \\
\hline Morris et al. (2001) & off & 634 & 72 & OR 0.85 & & & & & $\mathrm{x}$ & \\
\hline McFall et al. (2014) & off & 599 & 71 & & & & & $+^{*}$ & & \\
\hline Yang et al. (2011) & off & 594 & 76 & OR 1.00 & & & & & $\mathrm{x}$ & \\
\hline Sabayan et al. (2012) & off & 572 & 85 & & $-{ }^{*}$ & & & & $\mathrm{x}$ & \\
\hline Yasar et al. (2011) & off & 337 & 74 & & + & + & + & $+{ }^{*}$ & $\mathrm{x}$ & \\
\hline
\end{tabular}

Studies are from largest to smallest sample size.

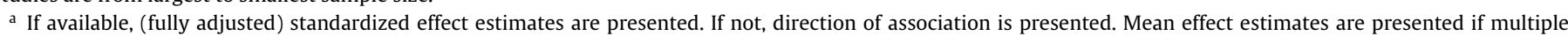
results were available for the same cognitive domain.

$+:$ higher PP associated with worse cognitive function.

-: higher PP associated with better cognitive function.

$=:$ no association between PP and cognitive function; direction of association not indicated in original manuscript.

b Pase et al. (2013) also evaluated the association between office PP and cognitive impairment; results for office PP were qualitatively similar to results for central PP.

c Study evaluated PP measured at a mean age of 58 (1) and 72 years (2), respectively.

${ }^{\mathrm{d}} \mathrm{U}$-shaped association between PP and cognitive decline.

Y, years; EF/A, executive function/attention; OR, odds ratio; off, office pulse pressure; cent, central pulse pressure.

$P<.05$

(62\% and $38 \%$ of significant studies were conducted in general healthy populations and selected clinical populations, respectively, versus $79 \%$ and $21 \%$ of the nonsignificant studies), total NOS score (for cross-sectional studies, mean score: 3.9 versus 3.6 points; for longitudinal studies, mean score: 6.0 versus 6.8 points) and, for longitudinal studies, duration of follow-up (7.5 versus 7.9 years) $(P$-values $>.13)$.

\section{Discussion}

\subsection{Main findings}

The present systematic review and meta-analysis had two main findings. First, with regard to the systematic review, most studies showed an independent association between greater arterial stiffness, as measured by cfPWV, baPWV, local carotid stiffness and PP, and markers of cerebral small vessel disease. In addition, studies found an association between higher cfPWV, baPWV and local carotid stiffness on the one hand and cognitive impairment on the other, but the strength of this association was relatively weak. In addition, results on the association between PP and cognitive impairment were inconsistent. Second, with regard to the meta-analysis, pooled analysis showed a statistically significant and strong association between greater arterial stiffness and markers of cerebral small vessel disease.

\subsection{Association between arterial stiffness and cerebral small vessel disease}

The results of the pooled analysis of cross-sectional studies showed that higher cfPWV, baPWV and local carotid stiffness were statistically significantly associated with markers of cerebral small vessel disease with standardized ORs of 1.29-1.32. These results strongly suggest that arterial stiffness is an important risk indicator of microvascular disease, with a strength of the association comparable to that of the association between arterial stiffness and measures of atherosclerosis (e.g. ankle-brachial index and coronary calcium score; Safar and O'Rourke, 2006).

\subsection{Association between arterial stiffness and cognitive impairment}

Some studies also showed an association between higher cfPWV, baPWV and local carotid stiffness on the one hand and cognitive impairment on the other. Estimated effect sizes were, however, relatively small and this association was statistically 
significant in a relatively low number of studies. This weak association may be due to the fact that mechanisms other than microvascular disease play a role in the pathobiology of cognitive impairment, including neurodegenerative pathology and the process of atherothrombosis.

In addition, PP was less consistently associated with cognitive impairment than cfPWV, baPWV and local carotid stiffness. Some studies showed an association between higher PP and worse cognitive function, whereas other studies found an inverted association, i.e. higher PP was associated with better cognitive function. These studies (Davis et al., 2003; Molander et al., 2010; Sabayan et al., 2012; van Bruchem-Visser et al., 2009) were all done in (biologically) older individuals. The presence of an inverted association in these individuals may have several explanations. Possibly, cognitive impairment or the process of neurodegeneration may cause dysregulation of blood pressure and, thereby, a decline in PP(Muller et al., 2014). Alternatively, in frail older individuals low blood pressure (including low PP) may, as a result of a dysfunctional vascular system, comprise perfusion of the brain, which may manifest as cognitive impairment (Muller et al., 2014).

\subsection{Methodological considerations}

Some methodological issues warrant consideration. First, the associations found might have been overestimated due to publication bias. The funnel plot of studies on the association between arterial stiffness and cerebral small vessel disease did not show (substantial) asymmetry (such asymmetry may indicate the presence of publication bias). However, studies on the association between arterial stiffness and cognitive impairment that found a significant association as compared to those studies which did not find such an association had a relatively smaller sample size. This may indicate the presence of publication bias, and suggests that the association between arterial stiffness and cognitive impairment may have been overestimated in earlier research. Second, most of the included studies were cross-sectional by design, which precludes a conclusion about the temporality of the studied associations. Nevertheless, the few studies with a longitudinal design did show that greater arterial stiffness was present before the presence of cerebral small vessel disease or cognitive impairment. Third, the present review included observational studies and we, therefore, cannot draw definite conclusions on causality. Fourth, a relatively high number of the studies did not adjust for systolic or mean blood pressure. Blood pressure is an important confounder in the association between arterial stiffness and microvascular disease. In those studies that did adjust for blood pressure, however, the association between arterial stiffness and cerebral small vessel disease/cognitive impairment remained. Fifth, results of studies on PP or cognitive impairment could not be pooled due to a large heterogeneity. Sixth, due to the design of the present systematic review and (aggregate-data) meta-analysis, it was not possible to make a direct comparison between different stiffness indices with regard to the strength of their association with cerebral small vessel disease/cognitive impairment. This issue requires further study. Seventh, only a limited number of studies measured local carotid stiffness, and ambulatory PP or central PP (almost all studies evaluated brachial office PP). Evidence for an association between these indices and microvascular brain disease is, therefore, weak and this issue requires further study. Finally, it is not fully clear why some studies found a significant association between arterial stiffness and cerebral small vessel disease/cognitive impairment and others did not. There were no differences between significant and nonsignificant studies with regard to the populations studied (i.e. general healthy populations versus selected clinical populations and age of the study population) and risk of bias (NOS scores).

\subsection{Assumptions underlying the studied associations}

Important assumptions underlying the associations evaluated in the present review are that markers of cerebral small vessel disease are valid indicators of cerebral microvascular damage, and that microvascular damage is involved in the pathobiology of cognitive impairment. Previous studies (Fisher, 1979; Wardlaw et al., 2013a, 2013b; Young et al., 2008) have indeed demonstrated that markers of cerebral small vessel disease represent both abnormal cerebral microvascular structure and function. For instance, studies have demonstrated that WMH, cerebral microbleeds and lacunar infarcts are associated with disruption and a greater permeability of the blood-brain layer as well as arteriosclerotic changes in small arteries/arterioles. In addition, previous studies (Gorelick et al., 2011; Mitchell, 2008; Mitchell et al., 2011; Wardlaw et al., 2013b) have shown a consistent association between cerebral small vessel disease and cognitive impairment.

\subsection{Underlying mechanisms}

The mechanism that may underlie the observed associations is that greater arterial stiffness leads to microcirculatory damage via an increased pulsatile pressure and flow load. This increased load may directly cause cerebral microvascular damage, despite bloodpressure-related protective autoregulatory mechanisms (Mitchell, 2008; O'Rourke and Safar, 2005; Tzourio et al., 2014). Alternatively, the increased pulsatile load may induce a microvascular remodelling response, which initially serves to limit the penetration of the pressure load on the microcirculatory system by raising vascular resistance. Yet, this protective response may ultimately become unfavourable, leading to impaired vasoreactivity and microvascular ischaemia. It is, moreover, likely that these mechanisms operate simultaneously.

\section{Conclusion}

The present systematic review and meta-analysis shows a consistent association across different cross-sectional studies between greater arterial stiffness and markers of cerebral small vessel disease. This supports the hypothesis that greater arterial stiffness is a contributor to microvascular brain disease. The strength of the association between greater arterial stiffness and cognitive impairment was, however, relatively weak, and might have been overestimated due to publication bias. Arterial stiffness may be a therapeutic target for the prevention of microvascular brain disease and, possibly, cognitive impairment. However, further well-powered longitudinal studies are warranted that investigate the temporality of the association between arterial stiffness, cerebral small vessel disease and cognitive impairment.

\section{Conflicts of interest}

None of the authors report any conflicts of interest.

\section{Acknowledgement}

Dr. Protogerou has received funding from the European Union Seventh Framework Programme ([FP7/2009-2013]) under grand agreement No. 299086.

\section{Appendix A. Supplementary data}

Supplementary data associated with this article can be found, in the online version, at http://dx.doi.org/10.1016/j.neubiorev. 2015.03.011. 


\section{References}

Aribisala, B.S., Morris, Z., Eadie, E., Thomas, A., Gow, A., Valdes Hernandez, M.C., Royle, N.A., Bastin, M.E., Starr, J., Deary, I.J., Wardlaw, J.M., 2014. Blood pressure, internal carotid artery flow parameters, and age-related white matter hyperintensities. Hypertension 63, 1011-1018.

Benetos, A., Watfa, G., Hanon, O., Salvi, P., Fantin, F., Toulza, O., Manckoundia, P., Agnoletti, D., Labat, C., Gautier, S., 2012. Pulse wave velocity is associated with 1 -year cognitive decline in the elderly older than 80 years: the PARTAGE study. Am. Med. Dir. Assoc. 13, 239-243.

Brisset, M., Boutouyrie, P., Pico, F., Zhu, Y., Zureik, M., Schilling, S., Dufouil, C., Mazoyer, B., Laurent, S., Tzourio, C., Debette, S., 2013. Large-vessel correlates of cerebral small-vessel disease. Neurology 80, 662-669.

Chrysohoou, C., Psaltopoulou, T., Panagiotakos, D., Pitsavos, C., Lazaros, G., Skoumas, J., Oikonomou, E., Poulidakis, E., Striggou, M., Stefanadis, C., 2012. Aortic elastic properties and cognitive function in elderly individuals: the Ikaria study. Maturitas (Epub ahead of print).

Coutinho, T., Turner, S.T., Kullo, I.J., 2011. Aortic pulse wave velocity is associated with measures of subclinical target organ damage. JACC Cardiovasc. Imaging 4, 754-761.

Davis, R.N., Massman, P.J., Doody, R.S., 2003. Effects of blood pressure on neuropsychological functioning in Alzheimer's disease. Arch. Clin. Neuropsychol. $18,19-32$.

DeCarli, C., Fletcher, E., Ramey, V., Harvey, D., Jagust, W.J., 2005. Anatomical mapping of white matter hyperintensities (WMH): exploring the relationships between periventricular WMH, deep WMH, and total WMH burden. Stroke 36, 50-55

De Leeuw, F.E., Barkhof, F., Scheltens, P., 2004. Alzheimer's disease - one clinical syndrome, two radiological expressions: a study on blood pressure. J. Neurol. Neurosurg. Psychiatry 75, 1270-1274

Elias, M.F., Robbins, M.A., Budge, M.M., Abhayaratna, W.P., Dore, G.A., Elias, P.K., 2009 Arterial pulse wave velocity and cognition with advancing age. Hypertension 53 668-673.

Freitag, M.H., Peila, R., Masaki, K., Petrovitch, H., Ross, G.W., White, L.R., Launer, L.J., 2006. Midlife pulse pressure and incidence of dementia: the Honolulu-Asia Aging Study. Stroke 37, 33-37.

Fisher, C.M., 1979. Capsular infarcts: the underlying vascular lesions. Arch. Neurol. $36,65-73$.

Fujiwara, Y., Chaves, P.H., Takahashi, R., Amano, H., Yoshida, H., Kumagai, S., Fujita, K., Wang, D.G., Shinkai, S., 2005. Arterial pulse wave velocity as a marker of poor cognitive function in an elderly community-dwelling population. J. Gerontol. A. Biol. Sci. Med. Sci. 60, 607-612.

Fukuhara, M., Matsumura, K., Ansai, T., Takata, Y., Sonoki, K., Akifusa, S., Wakisaka, M., Hamasaki, T., Fujisawa, K., Yoshida, A., Fujii, K., Iida, M., Takehara, T., 2006. Prediction of cognitive function by arterial stiffness in the very elderly. Circ. J. 70, 756-761.

Giang, L.M., Tighiouart, H., Lou, K.V., Agganis, B., Drew, D.A., Shaffi, K., Scott, T., Weiner, D.E., Sarnak, M.J., 2013. Measures of blood pressure and cognition in dialysis patients. Hemodial. Int. 17, 24-31.

Gorelick, P.B., Scuteri, A., Black, S.E., Decarli, C., Greenberg, S.M., Iadecola, C., Launer, L.J., Laurent, S., Lopez, O.L., Nyenhuis, D., Petersen, R.C., Schneider, J.A., Tzourio, C., Arnett, D.K., Bennett, D.A., Chui, H.C., Higashida, R.T., Lindquist, R., Nilsson, P.M., Roman, G.C., Sellke, F.W., Seshadri, S., 2011. Vascular contributions to cognitive impairment and dementia: a statement for healthcare professionals from the American Heart Association/American Stroke Association. Stroke 42, $2672-2713$.

Hanon, O., Haulon, S., Lenoir, H., Seux, M.L., Rigaud, A.S., Safar, M., Girerd, X., Forette, F., 2005. Relationship between arterial stiffness and cognitive function in elderly subjects with complaints of memory loss. Stroke 36, 2193-2197.

Hashimoto, J., Aikawa, T., Imai, Y., 2008. Large artery stiffening as a link between cerebral lacunar infarction and renal albuminuria. Am. J. Hypertens. 21, 1304-1309,

Henskens, L.H., Kroon, A.A., van Oostenbrugge, R.J., Gronenschild, E.H., Fuss-Lejeune, M.M., Hofman, P.A., Lodder, J., de Leeuw, P.W., 2008. Increased aortic pulse wave velocity is associated with silent cerebral small-vessel disease in hypertensive patients. Hypertension 52, 1120-1126.

Kalaitzidis, R.G., Karasavvidou, D., Tatsioni, A., Balafa, O., Pappas, K., Spanos, G., Pelidou, S.H., Siamopoulos, K.C., 2013. Risk factors for cognitive dysfunction in CKD and hypertensive subjects. Int. Urol. Nephrol. 45, 1637-1646.

Kearney-Schwartz, A., Rossignol, P., Bracard, S., Felblinger, J., Fay, R., Boivin, J.M. Lecompte, T., Lacolley, P., Benetos, A., Zannad, F., 2009. Vascular structure and function is correlated to cognitive performance and white matter hyperintensities in older hypertensive patients with subjective memory complaints. Stroke $40,1229-1236$

Kim, C.K., Lee, S.H., Kim, B.J., Ryu, W.S., Yoon, B.W., 2011. Age-independent association of pulse pressure with cerebral white matter lesions in asymptomatic elderly individuals. J. Hypertens. 29, 325-329.

Kim, S.H., Shim, J.Y., Lee, H.R., Na, H.Y., Lee, Y.J., 2012. The relationship between pulse pressure and leukoaraiosis in the elderly. Arch. Gerontol. Geriatr. 54, 206-209.

Kim, Y.S., Kim, D.H., Choi, B.H., Sohn, E.H., Lee, A.Y., 2009. Relationship between brachial-ankle pulse wave velocity and cognitive function in an elderly community-dwelling population with metabolic syndrome. Arch. Gerontol. Geriatr. 49, 176-179.

Kwon, H.S., Lim, Y.H., Kim, H.Y., Kim, H.T., Kwon, H.M., Lim, J.S., Lee, Y.J., Kim, J.Y, Kim, Y.S., 2014. Association of ambulatory blood pressure and heart rate with advanced white matter lessions in ischemic stroke patients. Am. J. Hypertens. $27,177-183$
Laugesen, E., Hoyem, P., Stausbol-Gron, B., Mikkelsen, A., Thrysoe, S., Erlandsen, M., Christiansen, J.S., Knudsen, S.T., Hansen, K.W., Kim, W.Y., Hansen, T.K., Poulsen, P.L., 2013. Carotid-femoral pulse wave velocity is associated with cerebral white matter lesions in type 2 diabetes. Diabetes Care 36, 722-728.

Lee, A.T., Chan, W.C., Chiu, H.F., Richards, M., Ng, S.P., Hui, L.Y., Chan, W.M., Lam, L.C., 2013. Widened pulse pressure is a potential risk factor for significant cognitive impairment among community-dwelling Chinese younger old people. J. Alzheimers Dis. 35, 687-696.

Liao, D., Cooper, L., Cai, J., Toole, J., Bryan, N., Burke, G., Shahar, E., Nieto, J., Mosley, T., Heiss, G., 1997. The prevalence and severity of white matter lesions, their relationship with age, ethnicity, gender, and cardiovascular disease risk factors: the ARIC Study. Neuroepidemiology 16, 149-162.

Matsumoto, M., Inoue, K., Moriki, A., 2007. Associations of brachial-ankle pulse wave velocity and carotid atherosclerotic lesions with silent cerebral lesions. Hypertens. Res. 30, 767-773.

McFall, G.P., Wiebe, S.A., Vergrote, D., Jhamandas, J., Westaway, D., Dixon, R.A., 2014. IDE (rs6583817) polymorphism and pulse pressure are independently and interactively associated with level and change in executive function in older adults. Psychol. Aging 29, 418-430.

Mitchell, G.F., 2008. Effects of central arterial aging on the structure and function of the peripheral vasculature: implications for end-organ damage. J. Appl. Physiol. (1985) 105, 1652-1660.

Mitchell, G.F., van Buchem, M.A., Sigurdsson, S., Gotal, J.D., Jonsdottir, M.K., Kjartansson, O., Garcia, M., Aspelund, T., Harris, T.B., Gudnason, V., Launer, L.J., 2011. Arterial stiffness, pressure and flow pulsatility and brain structure and function: the Age, Gene/Environment Susceptibility - Reykjavik study. Brain 134, 3398-3407

Moher, D., Liberati, A., Tetzlaff, J., Altman, D.G., 2009. Preferred reporting items for systematic reviews and meta-analyses: the PRISMA statement. Ann. Intern. Med. 151, 264-269, W264.

Molander, L., Gustafson, Y., Lovheim, H., 2010. Low blood pressure is associated with cognitive impairment in very old people. Dement. Geriatr. Cogn. Disord. $29,335-341$.

Morris, M.C., Scherr, P.A., Hebert, L.E., Glynn, R.J., Bennett, D.A., Evans, D.A., 2001 Association of incident Alzheimer disease and blood pressure measured from 13 years before to 2 years after diagnosis in a large community study. Arch. Neurol. 58, 1640-1646.

Muller, M., Grobbee, D.E., Aleman, A., Bots, M., van der Schouw, Y.T., 2007. Cardiovascular disease and cognitive performance in middle-aged and elderly men. Atherosclerosis 190, 143-149.

Muller, M., Smulders, Y.M., de Leeuw, P.W., Stehouwer, C.D., 2014. Treatment of hypertension in the oldest old: a critical role for frailty? Hypertension 63, 433-441.

Naganuma, T., Takemoto, Y., Yamasaki, T., Shima, H., Shoji, T., Ishimura, E., Nishizawa, Y., Morino, M., Okamura, M., Nakatani, T., 2011. Factors associated with silent cerebral microbleeds in hemodialysis patients. Clin. Nephrol. 75, 346-355.

Nomura, K., Hamamoto, Y., Takahara, S., Kikuchi, O., Honjo, S., Ikeda, H., Wada, Y., Nabe, K., Okumra, R., Koshiyama, H., 2010. Relationship between carotid intimamedia thickness and silent cerebral infarction in Japanese subjects with type 2 diabetes. Diabetes Care 33, 168-170.

Obisesan, T.O., Obisesan, O.A., Martins, S., Alamgir, L., Bond, V., Maxwell, C., Gillum, R.F., 2008. High blood pressure, hypertension, and high pulse pressure are associated with poorer cognitive function in persons aged 60 and older: the Third National Health and Nutrition Examination Survey. J. Am. Geriatr. Soc. 56 501-509.

Ochi, N., Kohara, K., Tabara, Y., Nagai, T., Kido, T., Uetani, E., Ochi, M., Igase, M., Miki, T., 2010. Association of central systolic blood pressure with intracerebral small vessel disease in Japanese. Am. J. Hypertens. 23, 889-894.

Ogunniyi, A., Lane, K.A., Baiyewu, O., Gao, S., Gureje, O., Unverzagt, F.W., Murrell, J.R., Smith-Gamble, V., Hall, K.S., Hendrie, H.C., 2011. Hypertension and incident dementia in community-dwelling elderly Yoruba Nigerians. Acta Neurol. Scand. $124,396-402$.

O'Rourke, M.F., Safar, M.E., 2005. Relationship between aortic stiffening and microvascular disease in brain and kidney: cause and logic of therapy. Hypertension 46, 200-204.

Pase, M.P., Herbert, A., Grima, N.A., Pipingas, A., O'Rourke, M.F., 2012. Arterial stiffness as a cause of cognitive decline and dementia: a systematic review and meta-analysis. Intern. Med. J. 42, 808-815.

Pase, M.P., Stough, C., Grima, N.A., Harris, E., Macpherson, H., Scholey, A.B., Pipingas, A., 2013. Blood pressure and cognitive function: the role of central aortic and brachial pressures. Psychol. Sci. 24, 2173-2181.

Peters, R., Beckett, N., Fagard, R., Thijs, L., Wang, J.G., Forette, F., Pereira, L., Fletcher A., Bulpitt, C., 2013. Increased pulse pressure linked to dementia: further results from the Hypertension in the Very Elderly Trial - HYVET. J. Hypertens. 31, $1868-1875$

Poels, M.M., van Oijen, M., Mattace-Raso, F.U., Hofman, A., Koudstaal, P.J., Witteman, J.C., Breteler, M.M., 2007. Arterial stiffness, cognitive decline, and risk of dementia: the Rotterdam study. Stroke 38, 888-892.

Poels, M.M., Vernooij, M.W., Ikram, M.A., Hofman, A., Krestin, G.P., van der Lugt, A. Breteler, M.M., 2010. Prevalence and risk factors of cerebral microbleeds: an update of the Rotterdam scan study. Stroke 41, S103-S106.

Poels, M.M., Zaccai, K., Verwoert, G.C., Vernooij, M.W., Hofman, A., van der Lugt, A. Witteman, J.C., Breteler, M.M., Mattace-Raso, F.U., Ikram, M.A., 2012. Arterial stiffness and cerebral small vessel disease: the Rotterdam Scan Study. Stroke $43,2637-2642$. 
2012. Review Manager (RevMan) [Computer program]. Version 5.2. The Nordic Cochrane Centre, The Cochrane Collaboration, Copenhagen.

Qiu, C., Winblad, B., Viitanen, M., Fratiglioni, L., 2003. Pulse pressure and risk of Alzheimer disease in persons aged 75 years and older: a community-based, longitudinal study. Stroke 34, 594-599.

Rabkin, S.W., Jarvie, G., 2011. Comparison of vascular stiffness in vascular dementia, Alzheimer dementia and cognitive impairment. Blood Press. 20, 274-283.

Raz, N., Dahle, C.L., Rodrigue, K.M., Kennedy, K.M., Land, S., 2011. Effects of age, genes, and pulse pressure on executive functions in healthy adults. Neurobiol. Aging 32, 1124-1137.

Robbins, M.A., Elias, M.F., Elias, P.K., Budge, M.M., 2005. Blood pressure and cognitive function in an African-American and a Caucasian-American sample: the MaineSyracuse Study. Psychosom. Med. 67, 707-714.

Rosano, C., Watson, N., Chang, Y., Newman, A.B., Aizenstein, H.J., Du, Y., Venkatraman, V., Harris, T.B., Barinas-Mitchell, E., Sutton-Tyrrell, K., 2013. Aortic pulse wave velocity predicts focal white matter hyperintensities in a biracial cohort of older adults. Hypertension 61, 160-165.

Sabayan, B., Oleksik, A.M., Maier, A.B., van Buchem, M.A., Poortvliet, R.K., de Ruijter W., Gussekloo, J., de Craen, A.J., Westendorp, R.G., 2012. High blood pressure and resilience to physical and cognitive decline in the oldest old: the Leiden 85-plus Study. J. Am. Geriatr. Soc. 60, 2014-2019.

Safar, M.E., O’Rourke, M.F., 2006. Arterial stiffness in hypertension. Elsevier, Amsterdam.

Saji, N., Kimura, K., Shimizu, H., Kita, Y., 2012. Association between silent brain infarct and arterial stiffness indicated by brachial-ankle pulse wave velocity. Intern. Med. 51, 1003-1008.

Saji, N., Shimizu, H., Kawarai, T., Tadano, M., Kita, Y., Yokono, K., 2011. Increased brachial-ankle pulse wave velocity is independently associated with white matter hyperintensities. Neuroepidemiology 36, 252-257.

Scuteri, A., Tesauro, M., Guglini, L., Lauro, D., Fini, M., Di Daniele, N., 2013. Aortic stiffness and hypotension episodes are associated with impaired cognitive function in older subjects with subjective complaints of memory loss. Int. J. Cardiol. 169, 371-377.

Seo, W.K., Lee, J.M., Park, M.H., Park, K.W., Lee, D.H., 2008. Cerebral microbleeds are independently associated with arterial stiffness in stroke patients. Cerebrovasc. Dis. 26, 618-623.

Singer, J., Trollor, J.N., Baune, B.T., Sachdev, P.S., Smith, E., 2014. Arterial stiffness, the brain and cognition: a systematic review. Ageing Res. Rev. 15, 16-27.

Singer, J., Trollor, J.N., Crawford, J., O'Rourke, M.F., Baune, B.T., Brodaty, H., Samaras, K., Kochan, N.A., Campbell, L., Sachdev, P.S., Smith, E., 2013. The association between pulse wave velocity and cognitive function: the Sydney Memory and Ageing Study. PloS One 8, e61855.

Song, T.J., Kim, J., Kim, Y.D., Nam, H.S., Lee, H.S., Nam, C.M., Heo, J.H., 2013. The distribution of cerebral microbleeds determines their association with arterial stiffness in non-cardioembolic acute stroke patients. Eur. J. Neurol. 21, 463-469.

Sugawara, N., Yasui-Furukori, N., Umeda, T., Kaneda, A., Sato, Y., Takahashi, I., Matsuzaka, M., Danjo, K., Nakaji, S., Kaneko, S., 2010. Comparison of ankle-brachial pressure index and pulse wave velocity as markers of cognitive function in a community-dwelling population. BMC Psychiatry 10, 46

Taylor, C., Tillin, T., Chaturvedi, N., Dewey, M., Ferri, C.P., Hughes, A., Prince, M., Richards, M., Shah, A., Stewart, R., 2013. Midlife hypertensive status and cognitive function 20 years later: the Southall and Brent revisited study. J. Am. Geriatr. Soc. 61, 1489-1498.

Tsao, C.W., Seshadri, S., Beiser, A.S., Westwood, A.J., Decarli, C., Au, R., Himali, J.J., Hamburg, N.M., Vita, J.A., Levy, D., Larson, M.G., Benjamin, E.J., Wolf, P.A., Vasan,
R.S., Mitchell, G.F., 2013. Relations of arterial stiffness and endothelial function to brain aging in the community. Neurology 10, 984-991.

Tsivgoulis, G., Alexandrov, A.V., Wadley, V.G., Unverzagt, F.W., Go, R.C., Moy, C.S. Kissela, B., Howard, G., 2009. Association of higher diastolic blood pressure levels with cognitive impairment. Neurology 73, 589-595.

Tzourio, C., Laurent, S., Debette, S., 2014. Is hypertension associated with an accelerated aging of the brain? Hypertension 63, 894-903.

van Bruchem-Visser, R.L., Mattace-Raso, F.U., van der Cammen, T.J., 2009. High systolic and pulse pressure levels are associated with better cognitive performance in patients with probable Alzheimer's disease: a cross-sectional observational study in a geriatric outpatient population. Dement. Geriatr. Cogn. Disord. 28 , 320-324.

Van Dooren, M., Staals, J., De Leeuw, P.W., Kroon, A.A., Henskens, L.H., Van Oostenbrugge, R.J., 2014. Progression of brain microbleeds in essential hypertensive patients: a 2-year follow-up study. Am. J. Hypertens. (Epub ahead of print).

Verhaaren, B.F., Vernooij, M.W., de Boer, R., Hofman, A., Niessen, W.J., van der Lugt, A., Ikram, M.A., 2013. High blood pressure and cerebral white matter lesion progression in the general population. Hypertension 61, 1354-1359.

Waldstein, S.R., Rice, S.C., Thayer, J.F., Najjar, S.S., Scuteri, A., Zonderman, A.B., 2008 Pulse pressure and pulse wave velocity are related to cognitive decline in the Baltimore Longitudinal Study of Aging. Hypertension 51, 99-104.

Wardlaw, J.M., Smith, C., Dichgans, M., 2013a. Mechanisms of sporadic cerebral small vessel disease: insights from neuroimaging. Lancet Neurol. 12, 483-497.

Wardlaw, J.M., Smith, E.E., Biessels, G.J., Cordonnier, C., Fazekas, F., Frayne, R., Lindley, R.I., O’Brien, J.T., Barkhof, F., Benavente, O.R., Black, S.E., Brayne, C., Breteler, M., Chabriat, H., Decarli, C., de Leeuw, F.E., Doubal, F., Duering, M., Fox, N.C. Greenberg, S., Hachinski, V., Kilimann, I., Mok, V., Oostenbrugge, R., Pantoni, L., Speck, O., Stephan, B.C., Teipel, S., Viswanathan, A., Werring, D., Chen, C., Smith, C., van Buchem, M., Norrving, B., Gorelick, P.B., Dichgans, M., 2013b. Neuroimaging standards for research into small vessel disease and its contribution to ageing and neurodegeneration. Lancet Neurol., 822-838.

Watson, N.L., Sutton-Tyrrell, K., Rosano, C., Boudreau, R.M., Hardy, S.E. Simonsick, E.M., Najjar, S.S., Launer, L.J., Yaffe, K., Atkinson, H.H., Satterfield, S., Newman, A.B., 2011. Arterial stiffness and cognitive decline in well-functioning older adults. J. Gerontol. A: Biol. Sci. Med. Sci. 66, 1336-1342.

Wells, G.A., Shea, B., O'Connell, D., Peterson, J., Welch, V., Losos, M., Tugwell, P. The Newcastle-Ottawa Scale (NOS) for assessing the quality if nonrandomized studies in meta-analyses. Available from: URL: http://www.ohri.ca/programs/ clinical_epidemiology/oxford.htm

Yang, Y.H., Roe, C.M., Morris, J.C., 2011. Relationship between late-life hypertension, blood pressure, and Alzheimer's disease. Am. J. Alzheimers Dis. Other Demen. 26, 457-462.

Yasar, S., Ko, J.Y., Nothelle, S., Mielke, M.M., Carlson, M.C., 2011. Evaluation of the effect of systolic blood pressure and pulse pressure on cognitive function: the Women's Health and Aging Study II. PLoS ONE 6, e27976.

Young, V.G., Halliday, G.M., Kril, J.J., 2008. Neuropathologic correlates of white matter hyperintensities. Neurology 71, 804-811.

Zeki Al Hazzouri, A., Newman, A.B., Simonsick, E., Sink, K.M., Sutton Tyrrell, K., Watson, N., Satterfield, S., Harris, T., Yaffe, K., 2013. Pulse wave velocity and cognitive decline in elders: the Health, Aging, and Body Composition study. Stroke 44, 388-393.

Zhong, W., Cruickshanks, K.J., Schubert, C.R., Carlsson, C.M., Chappell, R.J., Klein, B.E. Klein, R., Acher, C.W., 2013. Pulse wave velocity and cognitive function in older adults. Alzheimer Dis. Assoc. Disord. 28, 44-49. 